\title{
Ossification of the yellow ligament in thoracic spine: a case report
}

\author{
Aydin Kazempour Azar ${ }^{1}$, Javad Aghazadeh ${ }^{1}$, Firouz Salehpoor ${ }^{1}$, \\ Amir Rezakhah ${ }^{1}$, Amir Kamalifar ${ }^{1}$, Saber Ramezanpour ${ }^{1}$, \\ Samar Kamalifar ${ }^{2}$ \\ 1 Department of Neurosurgery, School of Medicine, Nazlou Campus, \\ Urumia University of Medical Sciences, Urumia, IRAN \\ 2 Department of Anatomy, School of Medicine, Arak University of \\ Medical Sciences, Arak, IRAN
}

\section{ABSTRACT}

Ossifications of yellow ligament (OYL) and calcification of yellow ligament are relatively rare clinical entities, and can make sever morbidity surgical evaluation can relived the sign and symptom and improve life quality we present a patient with ossification of yellow ligament in level of T9 and T10 of thoracic spin.

\section{CASE PRESEnTATION}

A 54 years old woman with chief complaint of back pain and lower limbs paraesthesia from 9 month ago, past medical history was negative and in drug history only she used pain relief agent like NSAIDs or acetaminophen in clinical evaluation upper motor neurons sign is positive ( plantar reflex double extensor, deep tendon reflex in knee and achile reflex significantly increased +4 ) and no episode of bladder or anal dysfunction, in MRI of thoracic we found stenosis in level of T9- T 10 from posterior element compression ,extradural lesion which was isosignal in T1 hypo signal in T2 without enhancement with gadolinium( figure 1), for future evaluation CT of vertebral column with $3 d$ reconstruction show a tiny ossification in interlamina space which bulged to central canal ( figure 2 ), patient admitted to operation room in prone position under general anaesthesia standard laminectomy was done bony yellow ligament was removed thecal sac was decompressed, 2 days after surgery patient discharged back pain and paraesthesia was improved after 3 month lower limbs muscles strong before and after surgery was 5/5 upper motors sign improve immediately a day after surgery

\section{DISCUSSION}

A Symptomatic OYL usually is located at the lower thoracic spine $(38.5 \%)$ and the lumbar spine $(26.5 \%)$ and is rare at the cervical spine (0.9\%) (3). The detailed mechanism of OYL is unclear. There are several

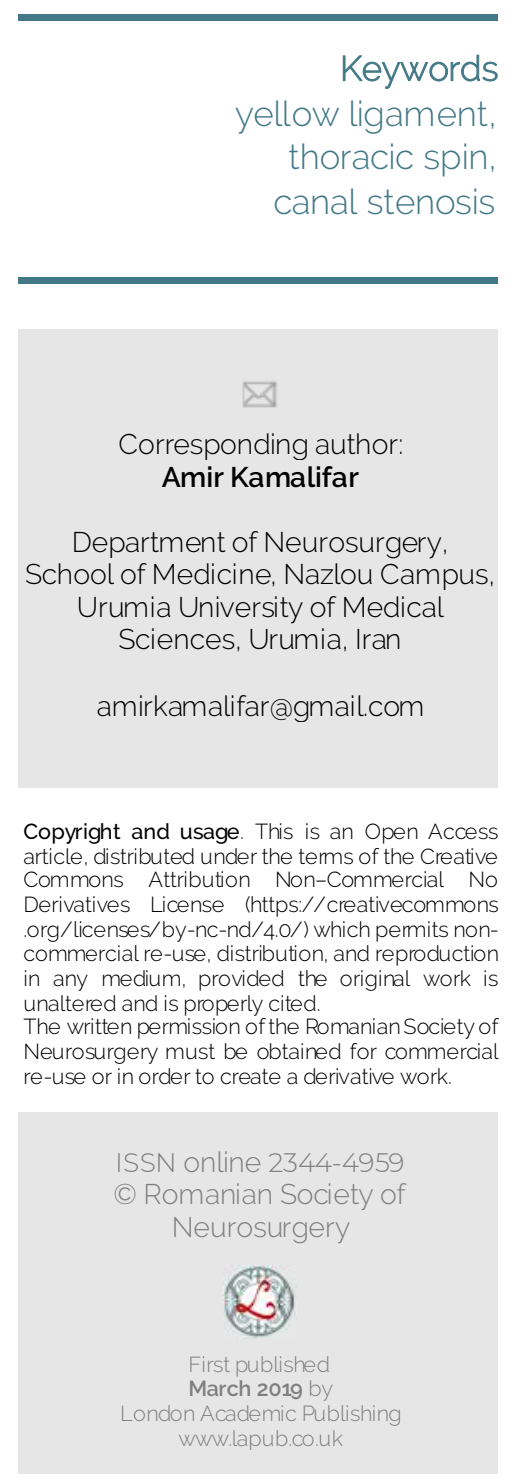


There are several reports that support the relationship between the growing factors of these ossification diseases and static and dynamic factors. $(4,5)$ The pathophysiology of OYL is similar to that of $Y L$ hypertro $\neg$ phy. Degeneration of the $Y L$ is due to hyper mobility of the poste-rior column, which results in collagen hyperplasia and hypertro - phy of the YL (5). Subsequent deposition of calcium pyrophosphate dehydrates and calcium hydroxyapatite occurs in the ligament, resulting in OYL (6). The pathology of $\mathrm{YL}$ hypertrophy includes fibro cartilaginous changes due to proliferation of type II collagen, ossification, and calcium crystal deposition, degeneration of collagen and elastic fibers, and chondroid metaplasia of ligament fi-broblasts.$(6,7)$ Ossification of the spinal ligament is characterized by heterotrophic bone formation in the spinal ligaments, which are normally composed of fibrous tissue Chondroid metapla-sia in YL hypertrophy appears to play a pivotal role in ligament ossification, as cartilage differentiation, hypertrophy, and cell death are followed by bone formation in the bone morphogenetic pathway(7). CT and MRI are useful tools for diagnosis, surgical planning, and evaluation of surgical prognosis. Reconstructed 2- dimensional and 3-dimensional CT images visualize the ossified lesion in all directions, which clarifies the actual shape and extent of OYL and OPLL and contributes to surgical planning Surgical treatment for symptomatic OYL and OPLL is recommended. Posterior decompression by partial laminectomy or laminoplasty with removal of OYL is effective for cases. $(8,9)$. in this case posterior decompression of spinal canal with standard laminectomy was done patient pain was improved immediately after the surgery and muscle force was improver after 3 month and tendon reflex and upper motor singe disappeared after surgery, the location of the pathology in lower thoracic similar to usual site of this pathology.

\section{Ethical Considerations}

Compliance with ethical guidelines All steps of this research were reviewed by Urmia University of Medical Sciences, ethical committee, with ethical code of 43256/43269.

\section{Funding}

This article was supported by Urmia University of Medical Sciences.
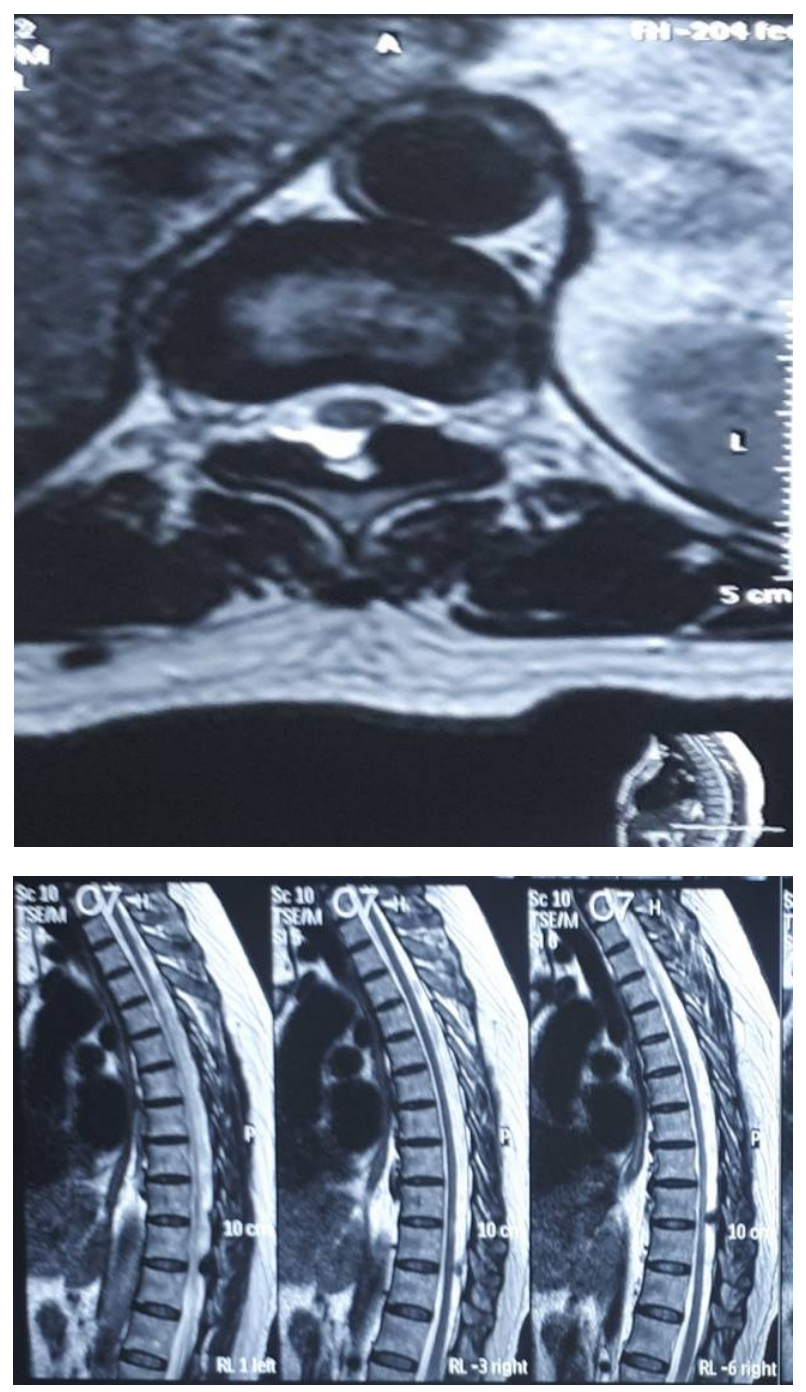

FIGURE 1: T 2 sequence of thoracic MRI sagital and axial view, hypo signal extradural lesion which compress the thecal sac from posterior

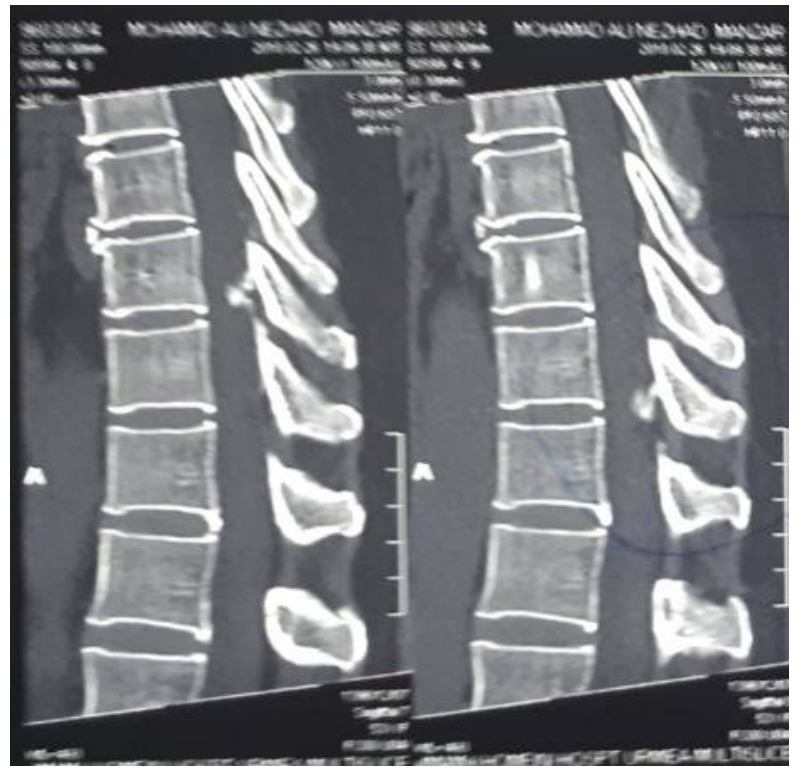




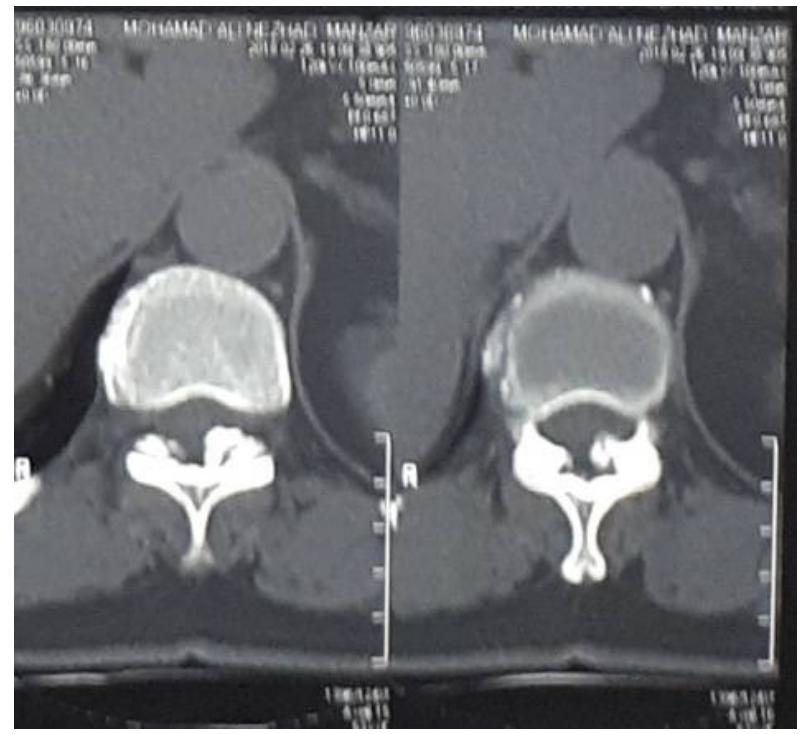

REFERENCES

1. 1. Guo JJ, Luk KD, Karppinen J, Yang H, Cheung KM. Prevalence, distribution, and morphology of ossification of the ligamentum flavum: a population study of one thousand seven hundred thirty-six magnetic resonance imaging scans. Spine Phila Pa; 35:51-56. 2010.

2. Inamasu J, Guiot BH. A review of factors predictive of surgical outcome for ossification of the ligamentum flavum of the thoracic spine.J Neurosurg Spine; 5:133-139. 2006.
3. al-Orainy IA, Kolawole T: Ossification of the ligament flavum. Eur J Raনdiol 29: 76-82, 1998.

4. Baur ST, Mai JJ, Dymecki SM: Combinatorial signaling through BMP receptor IB and GDF5: shaping of the distal mouse limb and the genetics of distal limb diversity. Development 127: 605-619, 2000.

5. Sanghvi AV, Chhabra HS, Mascarenhas AA, Mittal VK, Sangondimath GM Thoracic myelopathy due to ossification of ligamentum flavum: a retrospective analysis of predictors of surgical outcome and factors affecting preoperative neurological status. Eur SpineJ 20(2):205-215, 2011.

6. Chen Y, Lu XH, Yang LL, Chen DY Ossification of ligamentum flavum related to thoracic kyphosis after tuberculosis: case report and review of the literature. Spine, Phila Pa; 34(1): E41-E44 (2009).

7. Kang KC, Lee CS, Shin SK, Park SJ, Chung CH, Chung SS: Ossification of the ligamentum flavum of the thoracic spine in the Korean population. J Neurosurg Spine 14: 513-519, 2011.

8. Kuh SU, Kim YS, Cho YE, Jin BH, Kim KS, Yoon YS, et al.: Contributing factors affecting the prognosis surgical outcome for thoracic OLF. Eur Spine J 15: 485-491, 2006.

9. Mori K, Kasahara T, Mimura T, Nishizawa K, Murakami Y, Matsusue $Y$, et al.: Prevalence, distribution, and morphology of thoracic ossification of the yellow ligament in Japanese: results of CT-based cross-sectional study. Spine (Phila Pa 1976) 38: E1216-E1222, 2013. 